\title{
The C2 Pedicle Width, Pars Length, and Laminar Thickness in Concurrent Ipsilateral Ponticulus Posticus and High-Riding Vertebral Artery: A Radiological Computed Tomography Scan-Based Study
}

\author{
Manish Kundanmal Kothari ${ }^{1}$, Samir Surendranath Dalvie ${ }^{2}$, Santosh Gupta ${ }^{3}$, \\ Agnivesh Tikoo ${ }^{2}$, Deepak Kumar Singh ${ }^{2}$ \\ ${ }^{1}$ Department of Orthopaedics, Jaslok Hospital \& Research Centre, Mumbai, India \\ ${ }^{2}$ Department of Orthopaedics, P D Hinduja National Hospital \& MRC, Mumbai, India \\ ${ }^{3}$ Department of Radiology, P D Hinduja National Hospital \& MRC, Mumbai, India
}

Study Design: Retrospective radiological study.

Purpose: We aimed to determine the prevalence of ponticulus posticus (PP) and high-riding vertebral artery (HRVA) occurring simultaneously on the same side (PP+HRVA) and in cases of PP+HRVA, to assess C2 radio-anatomical measurements for C2 pars length, pedicle width, and laminar thickness.

Overview of Literature: PP and HRVA predispose individuals to vertebral artery injuries during atlantoaxial fixation. In cases of PP+HRVA, the construct options thus become limited.

Methods: Consecutive computed tomography scans ( $\mathrm{n}=210$ ) were reviewed for PP and HRVA (defined as an internal height of $<2 \mathrm{~mm}$ and an isthmus height of $<5 \mathrm{~mm}$ ). In scans with PP+HRVA, we measured the ipsilateral pedicle width, pars length, and laminar thickness and compared them with controls (those without PP or HRVA).

Results: PP was present in $14.76 \%$ and HRVA in $20 \%$ of scans. Of the 420 sides in 210 scans, PP+HRVA was present on 13 sides (seven right and six left). In scans with PP+HRVA, the C2 pars length was shorter compared with controls (13.69 mm in PP+HRVA vs. 20.65 $\mathrm{mm}$ in controls, $p<0.001)$. The mean C2 pedicle width was $2.53 \mathrm{~mm}$ in scans with PP+HRVA vs. $5.83 \mathrm{~mm}$ in controls $(p<0.001)$. The mean laminar thickness was 4.92 and $5.48 \mathrm{~mm}$ in scans with PP+HRVA and controls, respectively $(p=0.209)$.

Conclusions: The prevalence of PP+HRVA was approximately $3 \%$ in the present study. Our data suggest that, in such situations, C2 pedicle width and pars length create important safety limitations for a proposed screw, whereas the translaminar thickness appears safe for a proposed screw.

Keywords: Ponticulus posticus; High-riding vertebral artery; Axis, cervical vertebra; Cervical atlas

Received Mar 11, 2018; Revised Aug 7, 2018; Accepted Aug 15, 2018

Corresponding author: Manish Kundanmal Kothari

Department of Orthopaedics, Jaslok Hospital \& Research Centre, Mumbai, India

Tel: +91-22-24447178, Fax: +91-22-24440425, E-mail: ManishKKothari@gmail.com 


\section{Introduction}

The Goel-Laheri technique by Goel and Laheri [1], later modified by Harms and Melcher [2], and the Magerl technique by Magerl and Seemann [3] have revolutionized the way $\mathrm{C} 1-\mathrm{C} 2$ pathologies are treated. These techniques require expertise, not only in terms of operative skills, but also in the preoperative evaluation. Anatomical variations like ponticulus posticus (PP) (also known as arcuate foramen) and high-riding vertebral artery (HRVA) need to be identified before surgery. PP is a bony outgrowth arising from the superior margin of the posterior arch of the atlas that encircles the horizontal part of the third segment of the vertebral artery (VA) [4]. It may be complete or partial. It is of surgical importance when inserting the $\mathrm{C} 1$ lateral mass screw [5]. When the VA (intraosseous vertical part of the third segment) is anomalously located too medially, too posteriorly, and/or too high, it is termed as 'high riding' [6]. HRVA precludes the insertion of Magerl's transarticular screw and at times even a C2 pedicle screw [7]. When both these variations are present simultaneously on the same side, fixation options are limited and the surgeon needs to be aware and make important preoperative decisions regarding the construct. Numerous studies have described these variations individually $[4,6,8,9]$, but, to our knowledge, only one study has determined the prevalence of the co-occurrence of this entity [10]. To the authors' best knowledge, no study has evaluated the local surgical anatomic measurements in the presence of this combination. Hence, this study was undertaken to measure the C2 pedicle width, pars length, and laminar thickness in the presence of this specific combination, with the aim to address the anatomic safety concerns regarding the $\mathrm{C} 2$ pedicle, pars, and translaminar screws. The combination of ipsilateral concurrent PP with HRVA is henceforth referred to as 'PP+HRVA.

\section{Materials and Methods}

This study was approved by the institutional review board of authors' institution (IRB approval no., 2015011134). We screened 250 consecutive computed tomography (CT) scans of the cervical spine performed at P D Hinduja National Hospital \& MRC, Mumbai, which is a tertiary care center. All scans had been done on a General Electric LightSpeed VCT 64-slice helical scanner (General Electric, Fairfield, CT, USA). The scans were retrieved

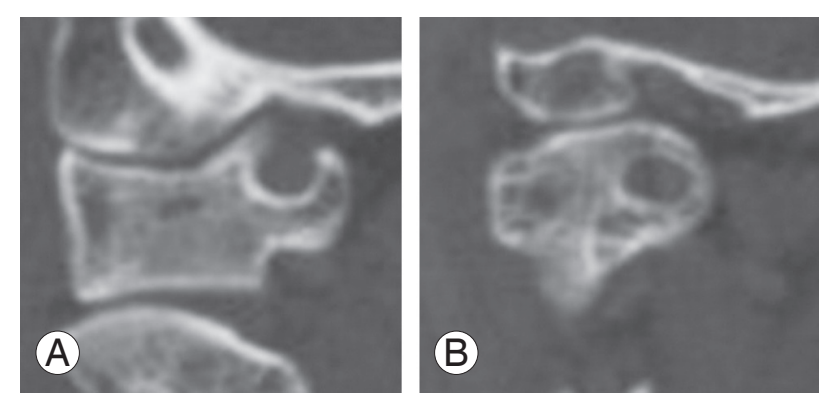

Fig. 1. (A, B) Complete and incomplete ponticulus posticus.

in digital format from the institutional picture archiving and communication system (PACS) server. All the scans were included in this study, with the exclusion criteria comprising (1) scans with prior surgery performed at the craniovertebral junction, (2) trauma or malignancy at the craniovertebral junction, (3) incomplete scans on the PACS server, and (4) subject age less than 18 years. A total of 210 scans were finally selected for the study.

There were 54 women and 156 men in the cohort; the mean age was 53 years (range, 18 to 88 years). The images were carefully inspected for the presence of HRVA and PP (complete or incomplete) (Fig. 1). HRVA was defined as per the criteria given by Neo et al. [11] (internal height less than $2 \mathrm{~mm}$ and/or isthmus height less than $5 \mathrm{~mm}$ ) (Fig. 2A). The above-mentioned measurements were taken from the parasagittal slice in which the isthmus was the thickest, as described by Neo et al. [11]. Scans with $\mathrm{PP}+\mathrm{HRVA}$ were identified, and from these scans we measured the ipsilateral C2 pedicle width (Fig. 2B) in axial cuts (the mediolateral diameter of the pedicle isthmus perpendicular to the pedicle axis) as described by Smith et al. [12]; C2 laminar thickness (Fig. 2C) in axial cuts at its isthmus (narrowest part) along its length as described by Dean et al. [13]; and the C2 pars length (Fig. 2D) on the sagittal cuts as described by Foley [14]. We chose the narrowest part (isthmus) of the pedicle and lamina for measurements because it was the limiting factor for safe estimated screw placement. Regarding the measurements of the $\mathrm{C} 2$ pedicle width and $\mathrm{C} 2$ laminar thickness in the $\mathrm{PP}+\mathrm{HRVA}$ group, we further classified this data as width lesser than or greater than $4 \mathrm{~mm}$ (usually used as the cutoff value for safe placement of a $3.5 \mathrm{~mm}$ pedicle screw and translaminar screw). We then compared these values with a control group $(n=60$; right, 30 ; left, 30$)$ taken from the parent sample for the right. This control group was randomly selected from the parent population that did not 

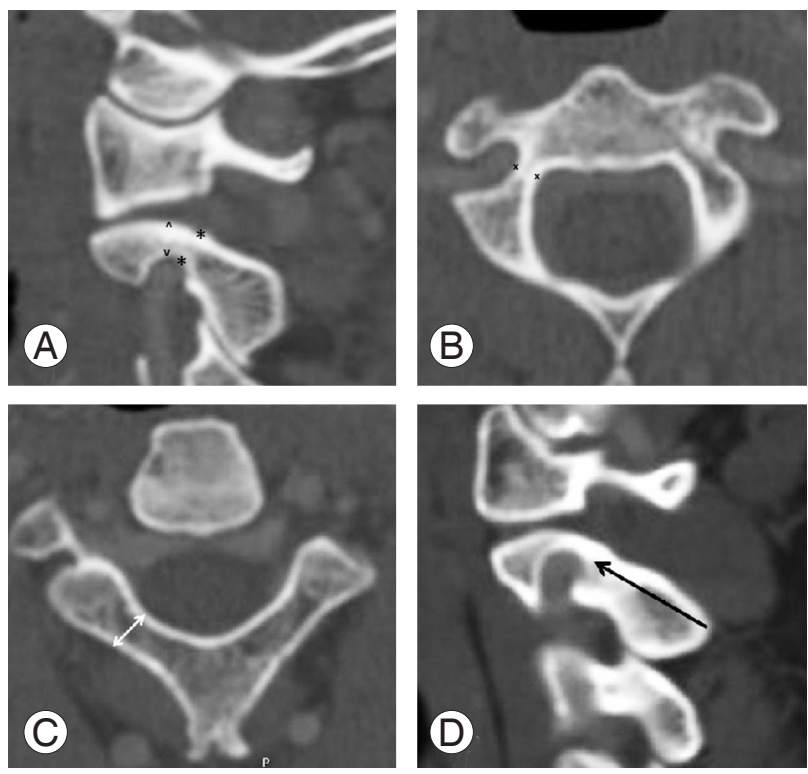

Fig. 2. Radio-anatomical measurements. (A) Measurement for highriding vertebral artery. Open arrows indicate the internal height and * indicates the isthmus height. (B) Measurement for the C2 pedicle width (x) at the isthmus. (C) Measurement for C2 laminar thickness (white arrow) at the isthmus. (D) Measurement for C2 pars length (black arrow).

have PP or HRVA on either side.

All the assessments were done by one radiologist and one fellowship-trained spine surgeon. Interobserver reliability testing was done using Cohen (kappa) correlation coefficients. All other statistical analyses were conducted using the chi-square test with Yates' correction, Fisher's exact test, and unpaired $t$-tests using the SPSS statistical package ver. 16.0 (SPSS Inc., Chicago, IL, USA). The level of significance was set at $p<0.05$.

\section{Results}

The interobserver reliability for PP had a kappa value of 0.841; kappa for interobserver reliability of HRVA was 0.956 .

\section{Ponticulus posticus}

PP was present in $14.76 \%$ of the total number (210) of scans. Of the 420 sides (left plus right) there were 41 sides (9.76\%) with PP (10 bilateral, 11 right, 10 left). In this subset, the mean age was 52.67 years (range, 18 to 83 years). There were 27 men and four women.

\section{High-riding vertebral artery}

HRVA was identified in $20 \%$ of the scans and in 59 of the 420 sides (17 bilateral, right 16 only, and left nine only). In this subset, the mean age was 53.83 years (range, 18 to 88 years), and there were 32 men and 10 women.

\section{Measurements in scans with ponticulus posticus+high- riding vertebral artery}

Of the 420 sides in the 210 scans, thirteen sides had PP+HRVA (two bilateral, five right, four left; a total of $3.09 \%$ ). In this subset of scans, the mean age was 40.9 years (range, 18 to 60 years), with nine men and two women. There was no statistical difference between occurrence on the left versus the right side $(p=0.7)$. For the scans positive for $\mathrm{PP}+\mathrm{HRVA}$, we measured the $\mathrm{C} 2$ pedicle width, laminar thickness, and C2 pars length on the same side and compared them with the control group $(n=60$; right, 30; left, 30).

\section{C2 pars length}

In scans with $\mathrm{PP}+\mathrm{HRVA}$, the mean $\mathrm{C} 2$ pars length was $13.69 \mathrm{~mm}$ (standard deviation $[\mathrm{SD}]=2.13 \mathrm{~mm}$; range, $10-18 \mathrm{~mm}$ ) versus $20.65 \mathrm{~mm}$ ( $\mathrm{SD}=2.79 \mathrm{~mm}$; range, $15-28$ $\mathrm{mm})$ in the control group. This difference was statistically significant $(p<0.001)$.

\section{C2 pedicle width}

In scans with $\mathrm{PP}+\mathrm{HRVA}$ the mean pedicle width was $2.53 \mathrm{~mm}$ ( $\mathrm{SD}=1.12 \mathrm{~mm}$; range, $1-5 \mathrm{~mm}$ ) versus $5.83 \mathrm{~mm}$ ( $\mathrm{SD}=1.52 \mathrm{~mm}$; range, $4-10 \mathrm{~mm}$ ) in the control group. This difference was statistically significant $(p<0.001)$. Only two out of 13 scans in the PP+HRVA group had a pedicle width $>4 \mathrm{~mm}$; all scans in the control group $(p<0.001)$ had such a pedicle width.

\section{C2 laminar thickness}

The mean laminar thickness in the PP+HRVA group was $4.92 \mathrm{~mm}$ ( $\mathrm{SD}=0.86 \mathrm{~mm}$; range, $3-6 \mathrm{~mm}$ ) versus $5.48 \mathrm{~mm}$ $(\mathrm{SD}=1.25 \mathrm{~mm}$; range, $4-8 \mathrm{~mm})$ in the control group. This difference was not statistically significant $(p=0.209)$. Only one scan in the PP+HRVA group had a laminar thickness $<4 \mathrm{~mm}$. The remaining scans in the PP+HRVA group and 
in the control group had laminar thicknesses $>4 \mathrm{~mm}$.

\section{Discussion}

Atlantoaxial fixation techniques carry a potential risk of injury to the VA [4]. Although these injuries can be asymptomatic, there is no reliable way to predict the outcome during surgery. The $\mathrm{C} 1$ lateral mass screw, when inserted by the classical Goel-Laheri technique by Goel and Laheri [1] (modified by Harms and Melcher [2]), has complications such as profuse bleeding from the venous plexus and the resultant poor visualization of landmarks and neuralgia [15]. To overcome these issues, some surgeons have suggested using a starting point at the dorsal aspect of the posterior arch of the atlas [16]. The ideal indication for this is when the $\mathrm{C} 1$ posterior arch is broad. However, Young et al. [5] reported that in some subjects, the PP may be mistaken for the broad posterior arch of $\mathrm{C} 1$ and injure the VA. In a meta-analysis of the prevalence of PP, the global prevalence was reported as $16.7 \%$ [4], which is very consistent with the findings of this study.

The Magerls C1-C2 transarticular screw provides the most rigid fixation, but its implantation is technically demanding, and the presence of HRVA is a contraindication for this technique [7]. According to the data presented by Yeom et al. [7], half of those with HRVA will also have a narrow $\mathrm{C} 2$ pedicle, whereas most subjects with a narrow C2 pedicle will have HRVA.

Yamazaki et al. [6] reported the prevalence of HRVA of $31 \%$ among patients undergoing craniovertebral junctional surgery, of which about half were identified in patients with skeletal anomalies. In the present study we found the overall prevalence of HRVA to be $20 \%$.

When PP and HRVA are present on the same side, there are important preoperative considerations to take into account for planning the implant construct. We found only one study which reported this combination [10]. Elgafy et al. [10], based on $100 \mathrm{CT}$ scan images, noted the prevalence of PP+HRVA to be at 5\%, similar to that found in this study. Interestingly, the reported prevalences of PP (43\%) and HRVA (32\%) by Elgafy et al. [10] was much higher than those in this study. They attributed this to the use of CT scans for the identification of PP; however, similar CT-based studies on the prevalence of PP have reported values ranging from $15 \%$ to $26 \%[17,18]$. Furthermore, one radiographic study from North America has reported the prevalence to be $45.3 \%$ [19]. One reason for such a high prevalence rate could be 'over-diagnosis.' Kim et al. [18] found small bony spicules on the posterior arch of the atlas in an additional seven percent of their subjects, but they did not consider these spicules to be PP. We also did not consider small spicules to be PP, as PP would not present a broad posterior arch of the atlas to the operating spine surgeon. No discussion of HRVA was provided by Elgafy et al. [10]

The combination of PP+HRVA poses a unique problem and thus needs to be described in detail. Plain radiographs and magnetic resonance imaging can easily miss this combination. When faced with such a situation, the C1C2 construct configuration needs to be planned carefully to avoid VA injury. According to our data, we noted an important safety concern with respect to the $\mathrm{C} 2$ pedicle screw, which upon scanning is invariably narrow in such cases; this increases the risk of injury to the VA. At this point, the $\mathrm{C} 2$ pars screw becomes a viable option. As per our data, the C2 pars length for a safely placed C2 pars screw would be shorter in cases of PP+HRVA $(13.69 \mathrm{~mm})$ than in controls $(20.65 \mathrm{~mm})$. It is important to note that a short pars screw length would provide an inferior hold relative to a standard 22-24 mm length. Supplementing this short screw construct with additional C1-2 wiring would seem prudent, although we have not studied this aspect to validate the idea. In a biomechanical study, Sim et al. [20] reported that an addition of C1-C2 modified Gallie's wiring added statistically significant stability in flexion-extension versus a bilateral transarticular screw construct alone. As an alternative to the pars screw, a C2 translaminar screw may also be used. In a cadaveric biomechanical study, some authors have reported that a construct comprising $\mathrm{C} 1$ lateral mass-C2 translaminar fixation provided equal stability when compared to posterior transarticular fixation [21,22]. Based on our results, in scans with PP+HRVA, the C2 lamina is capacious enough to accommodate a $3.5 \mathrm{~mm}$ screw or even a $4 \mathrm{~mm}$ screw. For a C1 lateral mass screw, the surgeon can opt for the conventional (Goel-Harms) technique [1,2]. Alternatively one can 'notch' the inferior aspect of the posterior $\mathrm{C} 1 \mathrm{arch}$ [15]. A more aggressive technique would be to dissect and elevate the VA out of the bony anomaly (PP) [7]. The authors of this study have routinely used the Goel-Harms technique in the presence of PP and have found it to be safe. Thus, for optimal management of craniovertebral pathologies, a surgeon needs to be trained in all these techniques. Some authors have advocated only unilateral 
fixation in the presence of VA anomalies [23], but we do not have any experience with such a construct.

In this study we have described the radio-anatomy pertinent to PP+HRVA. However, there were certain limitations to our study. First, we had a skewed male-to-female ratio despite using consecutive sampling for patient selection. This can partially be explained by the lower rates of healthcare-seeking by women [24]. Unfortunately, we do not have data regarding the total number of men and women seeking treatment at our center for comparison.

\section{Conclusions}

To conclude, the overall prevalence of PP+HRVA was $3.09 \%$. In such a situation, the C2 pedicle requires important safety consideration due to the small pedicle size, and the C2 pars length needed for safely placing a C2 pars screw is also short. However, the translaminar thickness is usually more than $4 \mathrm{~mm}$ and is safe for passage of a translaminar screw.

\section{Conflict of Interest}

No potential conflict of interest relevant to this article was reported.

\section{Acknowledgments}

The study was supported by the National Health \& Education Society and P D Hinduja National Hospital \& MRC, Mumbai, India.

\section{References}

1. Goel A, Laheri V. Plate and screw fixation for atlantoaxial subluxation. Acta Neurochir (Wien) 1994;129:4753.

2. Harms J, Melcher RP. Posterior C1-C2 fusion with polyaxial screw and rod fixation. Spine (Phila Pa 1976) 2001;26:2467-71.

3. Magerl F, Seemann PS. Stable posterior fusion of the atlas and axis by transarticular screw fixation. In: Kehr P, Weidner A, editors. Cervical spine 1. New York (NY): Springer-Verlag; 1987. p. 322-7.

4. Elliott RE, Tanweer O. The prevalence of the ponticulus posticus (arcuate foramen) and its importance in the Goel-Harms procedure: meta-analysis and review of the literature. World Neurosurg 2014;82:e335-43.

5. Young JP, Young PH, Ackermann MJ, Anderson PA, Riew KD. The ponticulus posticus: implications for screw insertion into the first cervical lateral mass. J Bone Joint Surg Am 2005;87:2495-8.

6. Yamazaki M, Koda M, Aramomi MA, Hashimoto M, Masaki Y, Okawa A. Anomalous vertebral artery at the extraosseous and intraosseous regions of the craniovertebral junction: analysis by three-dimensional computed tomography angiography. Spine (Phila Pa 1976) 2005;30:2452-7.

7. Yeom JS, Buchowski JM, Kim HJ, Chang BS, Lee CK, Riew KD. Risk of vertebral artery injury: comparison between C1-C2 transarticular and C2 pedicle screws. Spine J 2013;13:775-85.

8. Wakao N, Takeuchi M, Nishimura M, et al. Vertebral artery variations and osseous anomaly at the C1-2 level diagnosed by 3D CT angiography in normal subjects. Neuroradiology 2014;56:843-9.

9. Uchino A, Saito N, Watadani T, et al. Vertebral artery variations at the C1-2 level diagnosed by magnetic resonance angiography. Neuroradiology 2012;54:1923.

10. Elgafy H, Pompo F, Vela R, Elsamaloty HM. Ipsilateral arcuate foramen and high-riding vertebral artery: implication on C1-C2 instrumentation. Spine J 2014;14:1351-5.

11. Neo M, Matsushita M, Iwashita Y, Yasuda T, Sakamoto T, Nakamura T. Atlantoaxial transarticular screw fixation for a high-riding vertebral artery. Spine (Phila Pa 1976) 2003;28:666-70.

12. Smith ZA, Bistazzoni S, Onibokun A, Chen NF, Sassi M, Khoo LT. Anatomical considerations for subaxial (C2) pedicle screw placement: a radiographic study with computed tomography in 93 patients. J Spinal Disord Tech 2010;23:176-9.

13. Dean CL, Lee MJ, Robbin M, Cassinelli EH. Correlation between computed tomography measurements and direct anatomic measurements of the axis for consideration of C2 laminar screw placement. Spine J 2009;9:258-62.

14. Foley KT. A morphometric study of the C2 pedicle and pars: part 1 and 2 [Internet]. Montclair (NJ): SpineUniverse Marketing Team [cited 2015 Mar 3]. Available from: http://www.spineuniverse.com/professional/pathology/anatomy/morphometric-studyc2-pedicle-pars-part-1. 
15. Conroy E, Laing A, Kenneally R, Poynton AR. C1 lateral mass screw-induced occipital neuralgia: a report of two cases. Eur Spine J 2010;19:474-6.

16. Lee MJ, Cassinelli E, Riew KD. The feasibility of inserting atlas lateral mass screws via the posterior arch. Spine (Phila Pa 1976) 2006;31:2798-801.

17. Hong JT, Lee SW, Son BC, et al. Analysis of anatomical variations of bone and vascular structures around the posterior atlantal arch using three-dimensional computed tomography angiography. J Neurosurg Spine 2008;8:230-6.

18. Kim KH, Park KW, Manh TH, Yeom JS, Chang BS, Lee CK. Prevalence and morphologic features of ponticulus posticus in Koreans: analysis of 312 radiographs and 225 three-dimensional CT scans. Asian Spine J 2007;1:27-31.

19. Kuhta P, Hart J, Greene-Orndorff L, McDowell-Reizer B, Rush P. The prevalence of posticus ponticus: retrospective analysis of radiographs from a chiropractic health center. J Chiropr Med 2010;9:162-5.
20. Sim HB, Lee JW, Park JT, Mindea SA, Lim J, Park J. Biomechanical evaluations of various c1-c2 posterior fixation techniques. Spine (Phila Pa 1976) 2011;36:E401-7.

21. Lapsiwala SB, Anderson PA, Oza A, Resnick DK. Biomechanical comparison of four $\mathrm{C} 1$ to $\mathrm{C} 2$ rigid fixative techniques: anterior transarticular, posterior transarticular, $\mathrm{C} 1$ to $\mathrm{C} 2$ pedicle, and $\mathrm{C} 1$ to $\mathrm{C} 2$ intralaminar screws. Neurosurgery 2006;58:516-21.

22. Gorek J, Acaroglu E, Berven S, Yousef A, Puttlitz CM. Constructs incorporating intralaminar C2 screws provide rigid stability for atlantoaxial fixation. Spine (Phila Pa 1976) 2005;30:1513-8.

23. Song GS, Theodore N, Dickman CA, Sonntag VK. Unilateral posterior atlantoaxial transarticular screw fixation. J Neurosurg 1997;87:851-5.

24. Iyer A, Sen G, Ostlin P. The intersections of gender and class in health status and health care. Glob Public Health 2008;3 Suppl 1:13-24. 